\title{
A NEW METHODOLOGY CALLED DICE GAME OPTIMIZER FOR CAPACITOR PLACEMENT IN DISTRIBUTION SYSTEMS
}

Purpose. Shunt capacitors are installed in power system for compensating reactive power. Therefore, feeder capacity releases, voltage profile improves and power loss reduces. However, determination optimal location and size of capacitors in distribution systems is a complex optimization problem. In order to determine the optimum size and location of the capacitor, an objective function which is generally defined based on capacitor installation costs and power losses should be minimized According to operational limitations. This paper offers a newly developed metaheuristic technique, named dice game optimizer to determine optimal size and location of capacitors in a distribution network. Dice game optimizer is a game based optimization technique that is based on the rules of the dice game. References 27, tables 3, figures 3 .

Key words: capacitor placement, dice game optimizer, distribution systems, optimization algorithm.

Цель. Шунтирующие конденсаторы в энергосистеме устанавливаются для компенсации реактивной мощности. Следовательно, снижается емкость фидера, улучиается профиль напряжения и снижаются потери мощиости. Однако определение оптимального местоположения и размера конденсаторов в системах распределения является сложной задачей оптимизаци. Чтобы определить оптимальный размер и расположение конденсатора, целевую функцию, которая обычно определяется на основе затрат на установку конденсатора и потерь мощности, следует минимизировать в соответствии с эксплуатационными ограничениями. Данная статья предлагает недавно разработанный метаэвристический метод, называемый оптимизатором игры в кости, для определения оптимального размера и расположения конденсаторов в распределительной сети. Оптимизатор игры в кости - это игровой метод оптимизации, основанный на правилах игры в кости. Библ. 27, табл. 3, рис. 3.

Ключевые слова: размещение конденсаторов, оптимизатор игры в кости, системы распределения, алгоритм оптимизации.

Introduction. Capacitor banks are widely used in distribution systems for power loss reducing, voltage profile improving, feeder capacity releasing, reactive power compensating and power factor correcting. To get the maximum profit, capacitors should be optimally placed in distribution systems. Therefore, optimal place of capacitors should be determined with the help of an optimization technique. There are different objective functions and several solving methods for capacitor placement problem. These suggested objective functions are: minimize the power loss, minimize the capacitor installation cost, improve the voltage profile, reduce the burden on existing lines, maximize the network stability, and etc [1]. In general, capacitor placement problem is a hybrid optimization problem which should be effectively solved by a superior optimization technique. These techniques can be divided into four classes: analytical, numerical programming, heuristic and artificial intelligence techniques [2]. Heuristic techniques are quick and practical tools, which reduce the total search space and can result in a solution close to the optimal place of the capacitor with confidence [3]. In recent decade, metaheuristic algorithms have received a significant attention to solve the optimal capacitor bank placement problem. Compared with the common search techniques that require continuity, convexity and differentiability of the problem under investigation, metaheuristic algorithms do not require the derivative information and use stochastic rules to solve the problem. in this regard, capacitor placement problem has been solved by metaheuristic algorithms such as: genetic algorithm (GA) [4], immune system (IS) algorithm [5], particle swarm optimisation (PSO) [6], tabu search (TS) [6], memetic algorithm (MA) [7], graph search algorithm [8], teachinglearning-based optimization (TLBO) [9], and ant colony
(AC) [10]. Other algorithms are also proposed to solve the capacitor replacement problem such as spring search algorithm (SSA) [11, 12], orientation search algorithm (OSA) [13], Donkey Theorem Optimization (DTO) [14], Following Optimization Algorithm (FOA) [15], binary orientation search algorithm [16], and group optimization (GO) [17].

\section{Paper contribution and purposes.}

Due to the sufficiency of the metaheuristic techniques in optimization problems, in this study, the performance of a newly suggested metaheuristic technique which named dice game optimizer (DGO) is evaluated on capacitor placement problem. DGO is a game-based algorithm, which simulates rules of dice game and the searchers are a set of players.

This study proposes the dice game optimizer to obtain the optimal CBs placement and sizing in distribution systems. The proposed method aims to realize the following benefits:

1) studying the penetration of CBs to enhance the technical and economic issues of distribution systems;

2) technical objective is power loss reduction;

3) economic issue is considered as minimizing the costs of CBs;

4) applying the proposed method to standard radial distribution system;

5) increasing the awareness of the importance of penetration of $\mathrm{CBs}$ for enhancing the operation of electrical systems.

The rest of this paper has been organized as follows. Capacitor placement problem is defined In Section 2. DGO is introduced in section 3. Section 4, presented simulated results, and finally conclusion is given in Section 5. 


\section{Problem formulation.}

Objective function.

Since the major object of capacitor placement is to reduce the total losses and bring the buses voltages within the permissible bound while minimizing the total cost, so the objective function is defined as

$$
O F=k_{p} P_{\text {loss }}+\sum_{j=1}^{n} k_{j}^{c} Q_{j}^{c},
$$

where $O F$ is the total cost of the distribution network (\$), $k_{p}$ is the equivalent cost per unit of power loss $(\$ / \mathrm{kW})$, $P_{\text {loss }}$ is the power loss of the distribution network $(\mathrm{kW})$, $n$ is the number of buses, $Q_{j}^{c}$ is the size of the capacitor installed at bus $j$ and $k_{j}^{c}$ is the corresponding cost per kVar.

\section{Power loss calculation.}

In an assumed $\Pi$ model of the network in which I branch is attached to $k$ bus in one hand and to the $m$ bus on the other hand, $k$ bus is closer to the root bus that is the net power goes from $k$ to $m$ bus. Fig. 1 represents the power flow through the series impedance of the branch.

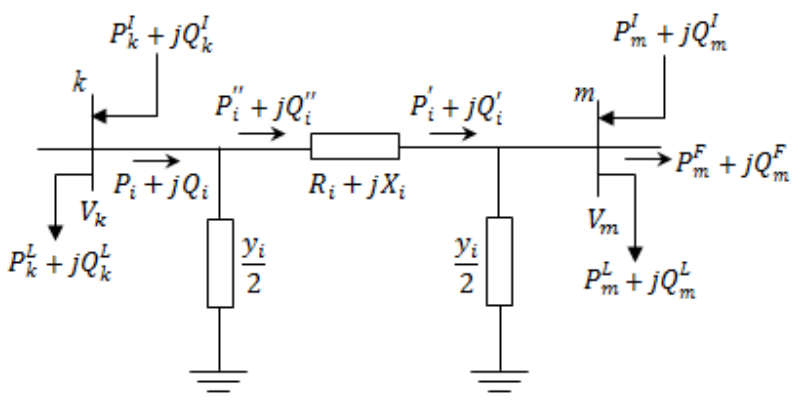

Fig. 1. П model of a network

These flows are represented in (2) and (3), elaborately

$$
\begin{array}{r}
P_{i}^{\prime}=P_{m}^{L}+P_{m}^{F}-P_{m}^{I}, \\
Q_{i}^{\prime}=Q_{m}^{L}+Q_{m}^{F}-Q_{m}^{I}-V_{m}^{2} \frac{y_{i}}{2},
\end{array}
$$

where $L, F$ and $I$ subscripts represents the load, the flow and the injection respectively. Branch $i$ let the power flow near bus $k$. This passage can be formulated as

$$
\begin{gathered}
P_{i}=P_{i}^{\prime \prime}=P_{i}^{\prime}+R_{i} \frac{P_{i}^{\prime 2}+Q_{i}^{\prime 2}}{V_{m}^{2}}, \\
Q_{i}=Q_{i}^{\prime \prime}-V_{k}^{2} \frac{y_{i}}{2}=Q_{i}^{\prime}+X_{i} \frac{P_{i}^{\prime 2}+Q_{i}^{\prime 2}}{V_{m}^{2}}-V_{k}^{2} \frac{Y_{i}}{2} .
\end{gathered}
$$

In order to calculate the power flow quantity in each branch of tree, it is computed recursively in a backward/anti clock-wise direction. Thus, the bus $m$ complex voltage is computed as

$$
V_{m}=\left[V_{k}-\frac{P_{i}^{\prime \prime} R_{i}+Q_{i}^{\prime \prime} X_{i}}{V_{k}^{*}}\right]-j\left[\frac{P_{i}^{\prime \prime} X_{i}-Q_{i}^{\prime \prime} R_{i}}{V_{k}^{*}}\right] .
$$

The strategy of finding the magnitude and angle of all buses voltages of the tree is to compute this complex voltage in a forward direction.

This computation is done iteratively again and again till the voltage difference at loop breaking points (breaking points of the tree) is placed within the acceptable limit. Hence the branch I active power loss $\left(P_{L i}\right)$ is measured as

$$
P_{L i}=P_{i}^{\prime \prime}-P_{i}^{\prime}=R_{i} \frac{P_{i}^{\prime 2}+Q_{i}^{\prime 2}}{V_{m}^{2}} .
$$

Accordingly, quantities of the system net active power loss is

$$
P_{L}=\sum_{i=1}^{N} P_{L i}
$$

Dice Game Optimizer [18]. Optimization algorithms is applied by researchers in various science such as energy [19, 20], power engineering [21-23], energy carriers [24, 25] and protection [26].

DGO is a game based optimization algorithm, which simulates rules of the old game named dice game. In DGO the initial position of the players is created randomly on the playing field (problem definition space).

In (9), the position «d» of player «i» is shown as $x_{i}^{d}$

$$
X_{i}=\left(x_{i}^{1}, \ldots, x_{i}^{d}, \ldots, x_{i}^{n}\right) .
$$

After the formation of the system, the rules are specified. Players compete with each other to determine the winner according to the rules of the game.

Calculation of each player's score.

In order to simulate the score of each player, a fitness function is used. It assigns higher score to the player with a better location. This parameter is computed according to

$$
\text { Score }_{i}=\frac{f_{i t}-f i t\left(\text { player }_{\text {best }}\right)}{\sum_{j=1}^{N} f i t_{j}-f i t\left(\text { player }_{\text {worst }}\right)},
$$

where Score $_{i}$ is the score of player $I, f_{i t}$ is the value of the fitness function, $N$ is the number of players, player $_{\text {best }}$ is the position of the best player and player $_{\text {worst }}$ is the position of the worst player.

These positions are indicated as

$$
\text { player }_{\text {best }}=\text { location of } \min \left(\text { fit }_{j}\right) \& j \in\{1: N\} \text {, }
$$

$$
\text { player }_{\text {worst }}=\text { location of } \max \left(\text { fit }_{j}\right) \& j \in\{1: N\} \text {. }
$$

Tossing dice for each player.

At this stage of the game each player tosses a dice once. A dice number is a discrete number between 1 and 6 that represents the number of player's guide of each player. The number of dice for each player is specified as

$$
\text { Dice }_{i}=K \& K \in\{123456\},
$$

where Dice $_{i}$ is the dice number for $i$-th player. This number is specified by $K$.

Selection of the Guide's players for each player.

For each player, based on the number of dice $(K)$, guide players are selected randomly among the players. These players are specified as

$$
X_{\text {Guide }_{i}}^{k}=X_{1}: X_{K},
$$

where $X_{\text {Guide }_{i}}^{k}$ is the position guide player number $k$ of player «i»».

Update of the position of each player.

Now $X^{i, d}$ is calculated as 


$$
X^{i, d}=X_{0}^{i, d}+\sum_{k=1}^{\text {Dice }_{i}}\left(r_{k}\left(X^{i, d}-X_{\text {Guide }_{i}}^{k, d}\right) \operatorname{sign}\left(\text { Score }_{i}-\text { Score }_{\text {Guide }_{k}}\right)\right),
$$

where $r_{k}$ is the random number with normal distribution in the interval [0-1] and Score $_{\text {Guide }_{k}}$ is the score of guide player number $k$.

Simulations and results. The case study that is considered in this paper is a $12.66 \mathrm{kV}$ and 33-bus distribution network shown in Fig. 2. The total active and reactive loads of this system are $3715 \mathrm{~kW}$ and $2300 \mathrm{kVar}$, respectively. In this network, the power losses are $201.8925 \mathrm{~kW}$. The system information has been adopted from [27]. The standard capacitors information is shown in Table 1. The performance of DGO is compared by the results obtained by $\mathrm{PSO}$, which this comparison is specified in Table 2.

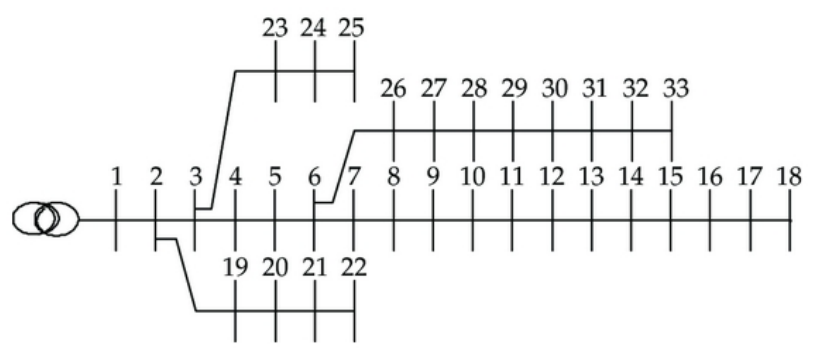

Fig. 2. Schematic of the 33-bus radial network

Table 1

\begin{tabular}{|c|c|c|c|c|c|c|}
\hline \multicolumn{7}{|c|}{ Standard capacitors information } \\
\hline$j$ & 1 & 2 & 3 & 4 & 5 & 6 \\
\hline$Q_{j}^{c}, \mathrm{kVar}$ & 150 & 300 & 450 & 600 & 750 & 900 \\
\hline$k_{j}^{c}, \$ / \mathrm{kVar}$ & 0.5 & 0.35 & 0.253 & 0.22 & 0.276 & 0.183 \\
\hline
\end{tabular}

Table 2

The simulation results of DGO and PSO

\begin{tabular}{|c|c|c|c|}
\hline Index & Uncompensated & \multicolumn{2}{|c|}{ Algorithm } \\
\hline & & DGO & PSO \\
\hline Annual cost, $\$$ & 33917.94 & 22573.54 & 22861.93 \\
\hline Network loss, $\mathrm{kW}$ & 201.8925 & 131.5359 & 132.4847 \\
\hline Net saving, $\$$ & N.A & 11344.40 & 11056.01 \\
\hline Avg. time, $\mathrm{s}$ & N.A & 53.43 & 58.39 \\
\hline
\end{tabular}

Over 30 independent runs, the best performance of DGO is 22573.54 \$ while PSO reaches to 22861.93 \$. It is clear that DGO gives better results than PSO. In solve the capacitor placement by DGO, the power losses are $131.5359 \mathrm{~kW}$ while in the solve the capacitor placement by PSO the power losses are $132.4847 \mathrm{~kW}$. Table 3 lists the installed $\mathrm{kVar}$ at each bus of the network.

Table 3

\begin{tabular}{|c|c|c|c|}
\hline \multicolumn{2}{|c|}{ Optimal capacitor placement results } \\
\hline DGO & \multicolumn{2}{c|}{ PSO } \\
\hline Bus number & Capacitor (kVar) & Bus number & Capacitor (kVar) \\
\hline 11 & 600 & 2 & 900 \\
\hline 24 & 450 & 7 & 450 \\
\hline 30 & 600 & 15 & 300 \\
\hline 33 & 300 & 29 & 450 \\
\hline- & - & 31 & 450 \\
\hline
\end{tabular}

Based on the DGO result, the value of the installed capacitor at buses $11,24,30$ and 33 is $600,450,600$ and $300 \mathrm{kVar}$, respectively. In this case, the 33-bus distribution network is compensated by $1950 \mathrm{kVar}$ of capacitor. According to the PSO result, the value of installed capacitor at compensated buses 2, 7, 15, 29 and 31 is $900,450,300,450$ and $450 \mathrm{kVar}$, respectively. This means that the 33-bus distribution network is compensated by $2550 \mathrm{kVar}$ of capacitor. Voltage profile of 33-bus distribution network shown in Fig. 3.

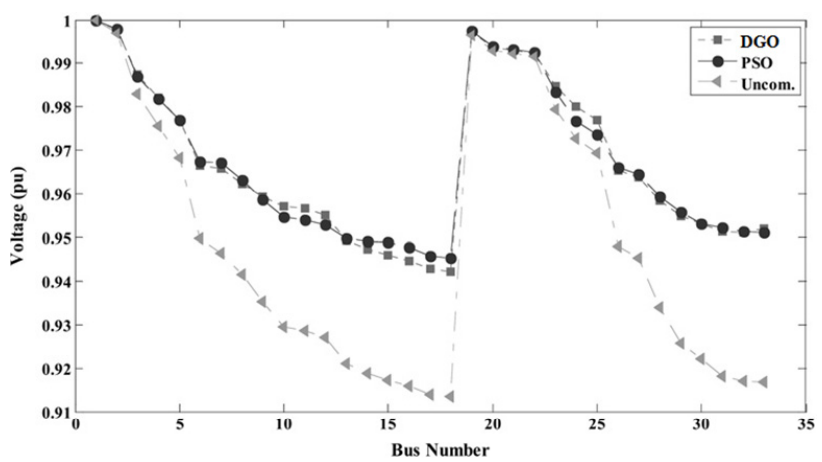

Fig. 3. Voltage profile of the 33-bus radial network

Conclusion. This paper proposes a new methodology for capacitor placement in distribution networks in order to power loss reduction and modify the voltage profile. The proposed methodology, which has applied here, is based on a new metaheuristic optimization technique, named dice game optimizer. In the simulation, it is looked that the results obtained by dice game optimizer are more precise than the results reported in the current literature. The convergence rate of dice game optimizer is good and it is looked that dice game optimizer solves the problem in less computational time than the other investigated techniques. As regard dice game optimizer is an efficient and rather simple algorithm, it would be suggested for various applications of power system engineering problems.

\section{REFERENCES}

1. Aman M.M., Jasmon G.B., Bakar A.H.A., Mokhlis H., Karimi M. Optimum shunt capacitor placement in distribution system - A review and comparative study. Renewable and Sustainable Energy Reviews, 2014, vol. 30, pp. 429-439. doi: 10.1016/j.rser.2013.10.002.

2. Ng H.N., Salama M.M.A., Chikhani A.Y. Classification of capacitor allocation techniques. IEEE Transactions on Power Delivery, 2000, vol. 15, no. 1, pp. 387-392. doi: 10.1109/61.847278.

3. Da Silva I.C., Carneiro S., de Oliveira E.J., de Souza Costa J., Pereira J.L.R., Garcia P.A.N. A heuristic constructive algorithm for capacitor placement on distribution systems. IEEE Transactions on Power Systems, 2008, vol. 23, no. 4, pp. 16191626. doi: 10.1109/tpwrs.2008.2004742.

4. Haghifam M.-R., Malik O.P. Genetic algorithm-based approach for fixed and switchable capacitors placement in distribution systems with uncertainty and time varying loads. IET Generation, Transmission \& Distribution, 2007, vol. 1, no. 2, p. 244. doi: 10.1049/iet-gtd:20045267.

5. Shyh-Jier Huang. An immune-based optimization method to capacitor placement in a radial distribution system. IEEE Transactions on Power Delivery, 2000, vol. 15, no. 2, pp. 744749. doi: 10.1109/61.853014.

6. Lee C.-S., Ayala H.V.H., dos S. Coelho L. Capacitor placement of distribution systems using particle swarm optimization approaches. International Journal of Electrical 
Power \& Energy Systems, 2015, vol. 64, pp. 839-851. doi: 10.1016/j.ijepes.2014.07.069.

7. Mendes A., Franca P.M., Lyra C., Pissarra C., Cavellucci C. Capacitor placement in large-sized radial distribution networks. IEE Proceedings - Generation, Transmission and Distribution, 2005, vol. 152, no. 4, p. 496. doi: 10.1049/ip-gtd:20059015.

8. Carlisle J. C., El-Keib A.A. A graph search algorithm for optimal placement of fixed and switched capacitors on radial distribution systems. IEEE Transactions on Power Delivery, 2000, vol. 15, no. 1, pp. 423-428. doi: 10.1109/61.847284.

9. Sultana S., Roy P.K. Optimal capacitor placement in radial distribution systems using teaching learning based optimization. International Journal of Electrical Power \& Energy Systems, 2014, vol. 54, pp. 387-398. doi: 10.1016/j.ijepes.2013.07.011.

10. Kaur D., Sharma J. Multiperiod shunt capacitor allocation in radial distribution systems. International Journal of Electrical Power \& Energy Systems, 2013, vol. 52, pp. 247-253. doi: 10.1016/j.ijepes.2013.03.026.

11. Dehghani M., Montazeri Z., Dehghani A., Nouri N., Seifi A. BSSA: Binary spring search algorithm. 2017 IEEE 4th International Conference on Knowledge-Based Engineering and Innovation (KBEI), Dec. 2017. doi: 10.1109/kbei.2017.8324977.

12. Dehghani M., Montazeri Z., Dehghani A., Seifi A. Spring search algorithm: A new meta-heuristic optimization algorithm inspired by Hooke's law. 2017 IEEE 4th International Conference on Knowledge-Based Engineering and Innovation (KBEI), Dec. 2017. doi: 10.1109/kbei.2017.8324975.

13. Dehghani M., Montazeri Z., Malik O.P., Ehsanifar A., Dehghani A. OSA: Orientation Search Algorithm. International Journal of Industrial Electronics, Control and Optimization, 2019, vol. 2, pp. 99-112.

14. Dehghani M., Mardaneh M., Malik O.P., NouraeiPour S.M. DTO: Donkey Theorem Optimization. 2019 27th Iranian Conference on Electrical Engineering (ICEE), Apr. 2019, pp. 1855-1859. doi: 10.1109/iraniancee.2019.8786601.

15. Dehghani M., Mardaneh M., Malik O. FOA: Following Optimization Algorithm for solving power engineering optimization problems. Journal of Operation and Automation in Power Engineering, 2020, vol. 8, iss. 1, pp. 57-64. doi: 10.22098/JOAPE.2019.5522.1414.

16. Dehghani M., Montazeri Z., Malik O.P., Dhiman G., Kumar V. BOSA: Binary Orientation Search Algorithm International. Journal of Innovative Technology and Exploring Engineering, 2019, vol. 9, iss. 1, pp. 5306-5310. doi: 10.35940/ijitee.A4215.119119.

17. Dehghani M., Montazeri Z., Dehghani A., Malik O.P. GO: Group Optimization. Gazi University Journal of Science, 2020, vol. 33 .

18. Dehghani M., Montazeri Z., Malik O.P. DGO: Dice Game Optimizer. Gazi University Journal of Science, 2019, vol. 32, pp. 871-882. doi: 10.35378/gujs.484643.

19. Dehghani M., Montazeri Z., Malik O.P. Energy commitment: a planning of energy carrier based on energy consumption. Electrical engineering \& electromechanics, 2019 , no.4, pp. 69-72. doi: 10.20998/2074-272X.2019.4.10.

20. Montazeri Z., Niknam T. Optimal utilization of electrical energy from power plants based on final energy consumption using gravitational search algorithm. Electrical engineering \& electromechanics, 2018, no.4, pp. 70-73. doi: 10.20998/2074272X.2018.4.12.
21. Dehbozorgi S., Ehsanifar A., Montazeri Z., Dehghani M., Seifi A. Line loss reduction and voltage profile improvement in radial distribution networks using battery energy storage system. 2017 IEEE 4th International Conference on Knowledge-Based Engineering and Innovation (KBEI), Dec. 2017. doi: 10.1109/kbei.2017.8324976.

22. Dehghani M., Mardaneh M., Montazeri Z., Ehsanifar A., Ebadi M.J., Grechko O.M. Spring search algorithm for simultaneous placement of distributed generation and capacitors. Electrical engineering \& electromechanics, 2018, no.6, pp. 6873. doi: 10.20998/2074-272X.2018.6.10.

23. Dehghani M., Montazeri Z., Malik O.P. Optimal sizing and placement of capacitor banks and distributed generation in distribution systems using spring search algorithm. International Journal of Emerging Electric Power Systems, 2020, vol. 21. doi: 10.1515/ijeeps-2019-0217.

24. Dehghani M., Montazeri Z., Ehsanifar A., Seifi A.R., Ebadi M.J., Grechko O.M. Planning of energy carriers based on final energy consumption using dynamic programming and particle swarm optimization. Electrical engineering \& electromechanics, 2018, no.5, pp. 62-71. doi: 10.20998/2074-272X.2018.5.10.

25. Montazeri Z., Niknam T. Energy carriers management based on energy consumption. 2017 IEEE 4th International Conference on Knowledge-Based Engineering and Innovation (KBEI), Dec. 2017. doi: 10.1109/kbei.2017.8325036.

26. Ehsanifar A., Dehghani M., Allahbakhshi M. Calculating the leakage inductance for transformer inter-turn fault detection using finite element method. 2017 Iranian Conference on Electrical Engineering (ICEE), May 2017. doi: 10.1109/iraniancee.2017.7985256.

27. Baran M.E., Wu F.F. Network reconfiguration in distribution systems for loss reduction and load balancing. IEEE Transactions on Power Delivery, 1989, vol. 4, no. 2, pp. 14011407. doi: 10.1109/61.25627.

Received 24.12.2019

M. Dehghani ${ }^{1}$, Candidate of Power Engineering, PhD Student, Z. Montazeri ${ }^{1}$, Candidate of Power Engineering, PhD Student, O.P. Malik ${ }^{2}$, Doctor of Power Engineering, Professor, Kamal Al-Haddad ${ }^{3}$, FIEEE, FRSC, FACE, Professor, Josep M. Guerrero ${ }^{4}$, Doctor of Power Electronics, Professor, G. Dhiman ${ }^{5}$, Doctor of Computer Engineering, Assistant

Professor,

${ }^{1}$ Department of Electrical and Electronics Engineering,

Shiraz University of Technology, Shiraz, Iran,

e-mail: adanbax@gmail.com, Z.Montazeri@sutech.ac.ir

${ }^{2}$ Department of Electrical Engineering,

University of Calgary, Calgary Alberta Canada,

e-mail: maliko@ucalgary.ca

${ }^{3}$ École de technologie supérieur,

University of Quebec, Montreal, Canada,

e-mail: kamal.al-haddad@etsmtl.ca

${ }^{4}$ Department of Energy Technology,

Aalborg University, Aalborg, Denmark,

e-mail: joz@et.aau.dk

${ }^{5}$ Department of Computer Science,

Government Bikram College of Commerce,

Patiala, Punjab 147004, India,

e-mail: gaurav.dhiman@thapar.edu

\section{How to cite this article:}

Dehghani M., Montazeri Z., Malik O.P., Al-Haddad K., Guerrero J. M., Dhiman G. A new methodology called dice game optimizer for capacitor placement in distribution systems. Electrical engineering \& electromechanics, 2020, no.1, pp. 61-64. doi: 10.20998/2074-272X.2020.1.10. 